\title{
Bhupinder Dawett: 'I would like to see oral health research embedded into general practice activity'
}

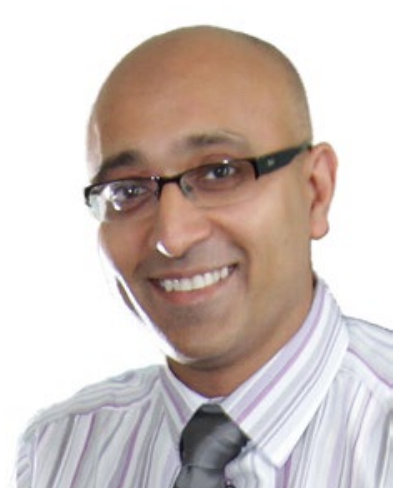

\section{Why did you choose dentistry?}

Strangely, dentistry was never really my first choice when I was at school. After completing A levels I went to university to study mathematics and statistics. After one term, realisation struck that it wasn't really for me and that I needed something more hands on. Following the departure from mathematics I was really undecided with regard to what to do career wise and it was just by chance that same week I had a dental appointment. During my visit I asked my newly qualified dentist if he wouldn't mind me sticking around for the day to see what he did.

He very kindly agreed, so one day turned into a week, then into a month, and several months, and that's how I chose dentistry. I wanted a profession with altruistic motives, which I still believe is the main reason for people entering into a healthcare-related profession.

\section{How do you make minimum intervention (MI) dentistry work in an NHS dental practice?}

To be honest this is the reason why we're now doing research, to find out issues of implementation and acceptability when trying to deliver a MID care pathway in general dental practice before we can run a more definitive trial. From experience when my

\author{
Bhupinder Dawett qualified in 1993 and has maintained working in \\ NHS general dental practice ever since. He is principal dentist at Hafren \\ House Dental Practice; a multi-surgery practice which focuses on minimum \\ intervention dentistry and practice-based research. Alongside this, Bhupinder \\ is currently a Doctoral Research fellow at the University of Sheffield, and also \\ a clinical lecturer on the distance-learning masters in Advanced Minimum \\ Intervention Dentistry at the Faculty of Dentistry, Oral and Craniofacial \\ Sciences at King's College London.
}

practice first started to go down the MI path, education was key with a need to understand and make sense of the evidence base supporting the service you provide and then being able to discuss this with your patients. That's not always easy for most dentists and certainly wasn't for me when I started because you're busy in practice and probably haven't developed the academic skills when you're working at the coal-face. Also I feel the dental practice team need to be aware and accepting of the MI options that can be provided to patients, and this needs to be supported by the practice management in making these MI options available (eg equipment, materials) for trained dental professionals to be in position to utilise them appropriately.

I also think we need to explain what MI actually is to patients, so that they can be well informed when consenting and accepting care. We used focus groups to help us understand patient perspectives, utilising independent researchers to come into the practice to run those focus groups to give us an idea of what patients actually want from our services. This has helped my practice team to understand how to promote MI using things like patient information leaflets.

Involving members of the wider practice team can help and, in this regard, building and developing your team is important. We have a dental therapist at our practice and making full use of their skills has been a positive influence. It's always a plus when your team sing from the same hymn sheet, and although there will always be some variation in the manner and way in which clinicians work, you want them all to be heading in the same direction. Having peer review meetings to discuss publications and developing techniques has really helped our practice team.

\section{What else can you do to make MI dentistry effective?}

That's a really interesting question as working in practice you begin to recognise that making something more 'effective' is not just related to the basic science of an intervention. Implementation is also key. So if we look just at MI caries management, then delivering MI dentistry is not just about one specific treatment or intervention, but is more akin to a complex intervention where there are a number of component parts such as detection, diagnosis, prevention, restoration, etc. It's important to research how these really interact in practice, and the numerous factors that play a role at practice level such as practice organisation, remuneration, regulatory issues, medico-legal concerns, 
etc. This is something that I along with my colleagues at the University of Sheffield will be investigating. So far initial work done has identified elements that will need further insight and understanding.

At my practice, the team have always been patient focused but before working in MI, we were treating the effects of dental caries rather than focussing on preventing it as a disease. After working for so many years with NHS patients and seeing such a number of patients you can begin to lose sense of what prevention is. You do fillings and think 'that's the way I treat the disease'. After a while you realise that treating the disease by just drilling and filling isn't really curing dental caries in a lot of people but just delaying further cavities.

\section{Are the patients receptive to $\mathrm{MI}$ ?}

Most patients I feel are, but getting the MI message across to patients can be a challenge. In the chair, you can say to the patient 'I can drill your tooth, or I can take this approach which may mean that we don't drill your tooth. Which would you prefer?' It's a no-brainer, but you have to inform patients that it's really their responsibility to maintain their oral health. We can only help them manage their disease and can't research, and its subsidary departments such as the Research Design Service, have really provide us great support. They were invaluable for my practice as they provided support from how to design a proposal, how to get ethical approval, information on how the research process works, and where to seek academic collaboration. Actually, in this country we are very fortunate to have a supporting organisation such as the NIHR which really fosters and aids applied health research activity at all levels including primary care.

If I was to advise others in practice I would start by saying that you need to begin somewhere and that is with a question something that you identify in your practice as a problem. This doesn't always have to be focussed on one specific clinical condition, and can be service related such as 'How do I run my service better for these particular patients?'

Once you have identified a problem, then the next stage would be to think, 'Have I got a potential solution?' Following on from this, more importantly ask yourself 'what research is required, and could I run the research study to answer that question?'

Most dentists I talk to state that they don't know how to come up with a research question, but in practice, I think one asks

\section{'We need to explain what MI actually is to patients'}

by ourselves cure their disease for them. I do believe that certain aspects of MI appeal to patients such as 'pain-free' treatment, utilisation of the dental team (thereby possibly improving access), the more holistic approach of MI, etc.

\section{How do you conduct research in practice?}

Most practices I suspect are unaware of how they can get involved in research or where to go. Certainly this is true of my experience when starting my research journey. There are organisations out there that can help you. For my practice, and especially our DCPs, the Oral and Dental Research Trust (ODRT) has been very supportive in helping us get projects off the ground. Also the National Institute for Health Research (NIHR), the nation's largest funder of health and care questions all the time. There are plenty of questions you could ask and it's all about being observational in your working environment. You'll come up with a whole load of questions that you ask subconsciously, but you just need to put that on paper and you'll probably come up with a reasonable project. It's always better to do this as a practice team where an exchange of ideas really is helpful.

If a practice does want to generate their own ideas then they can look at getting involved as part of larger trials that are looking to recruit patients on their study. Recruiting patients into such trials can be a barrier, especially when you have to randomise a patient. When you're giving them an intervention that isn't dictated by your choice or their choice, it's really decided by a computer. That can be a bit of an issue. It means you have to explain to them you don't know if the treatment they're getting is better or worse than the treatment they're not getting. The reason we're doing the research is that we don't know which one works. Also having a good team where staff members can be delegated duties such as screening, data storage, etc certainly eases the flow of research activity in a busy practice environment.

\section{What are you working on at the moment?}

I'm currently in the throes of a four-year NIHR Doctoral Research fellowship programme based at the University of Sheffield. As part of this I'm undertaking a $\mathrm{PhD}$ where we plan to to investigate the feasibility of providing MI dentistry to children with tooth decay in their permanent teeth. This will be a practice-based research study and I feel really fortunate to be working with very supportive colleagues at Sheffield Dental School, whilst I am still embedded in general dental practice. As I mentioned earlier my research will be assessing the management of children with caries and not as single component intervention but as a complete MID care pathway comprising of detection, diagnosis, prevention, restoration and recall. Also, in collaboration with the local LDC and NIHR, I'm involved in the development of a dental practice-based research network in our region

\section{In the next NHS contract, what changes would you like to see?}

Firstly, we need consensus on what 'quality' means in NHS general dental practice. The word quality can mean different things to different people and currently I think there is lack of high quality academic research and consensus on what quality in a dental service should look like. This needs to be agreed and then we can tailor and reward services appropriately. Personally, I would like to see the focus change to early disease identification and prevention, and again with a remuneration and regulatory system that reflects this. We need to really design a contract that helps focus care for high risk patients that possess a higher burden of disease. The current system of UDA target driven activity is far from the ideal system required to implement MI dentistry. I understand that the current UDA scenario may offer commissioning teams some measure of performance management, 
but the UDA is far from being an ideal measure of oral health and as such, what kind of performance is it really recording?

\section{If you were minister for health but with unlimited resources, what would you do with dentistry?}

It would be great if we had unlimited resources, but I don't think that's going to happen anytime soon. One of the biggest challenges we have is reducing oral health

\section{Who do you most admire and why?} Personally, I would say my parents and my wife. They all come from a working class background and have shown me the value of hard work, humility and dedication. I like to read a lot and although most of my reading seems to be dentally orientated I suppose I've been inspired by the writings of several people, including Mahatma Gandhi. Obviously I admire his thoughts on non-violence, altruism, interfaith tolerance, but his

\section{'You need to start somewhere and that is with a question'}

inequalities that persist across the population. I still believe that dentistry should have a place in a publicly funded NHS system.

If resources were unlimited then, if you're asking me what I would like to see, given that the NHS was meant to be free at the point of delivery, it would be nice to get rid of patient charges. We currently have an NHS system that is talked about and admired by most countries but is replicated by none. I would also certainly like to see oral health research somehow embedded into general practice activity, and the recommendations from such research findings to be adopted and implemented much more quickly in practice. book The story of my experiments with truth describes his life as an inquisitive researcher For me it's this spirit of inquisition, and how just deep reflection, observation, and changing one's own behaviour can lead to some very valuable insights.

Professionally, I'm very fortunate to be surrounded by many very hard-working, dedicated, and inspirational colleagues. Just listening to them makes me realise how much they give to the world of dentistry and oral healthcare. I have learned so much from many people at the University of Sheffield such as Professors Chris Deery and Zoe Marshman to name a few, Prof Avijit
Banerjee at King's Dental Institute, and also from my colleagues on our Derbyshire County Local Dental Committee that freely give their time to help others.

\section{What do you like to do in your own time?}

I don't get much of my own time! And I wish I was much better at the work-life balance thing. When I do manage to spend time away from dentistry, I like to read, walk my dog, cycle, and play golf. I live near a golf course so I'm very fortunate to be able to walk out and play a few holes of golf with my kids. I do like to cycle, and have a recumbent tricycle which on sunny days I like to take to into the Peak District near my practice.

\section{What are you most proud of?}

In addition to my wife and kids... my dental practice team. We spend probably just as much time with our working colleagues and in close proximity as we do with our family members, and I suspect most practice owners will tell you that treating patients is one thing but creating an environment for your staff to work harmoniously especially during periods of change can be at times tricky. For me it's really heart-warming to see how our practice team has grown and developed over many years, embracing changes and challenges. They still continue to evolve, contribute to research, and always go about caring for patients and fellow colleagues with empathy and compassion.

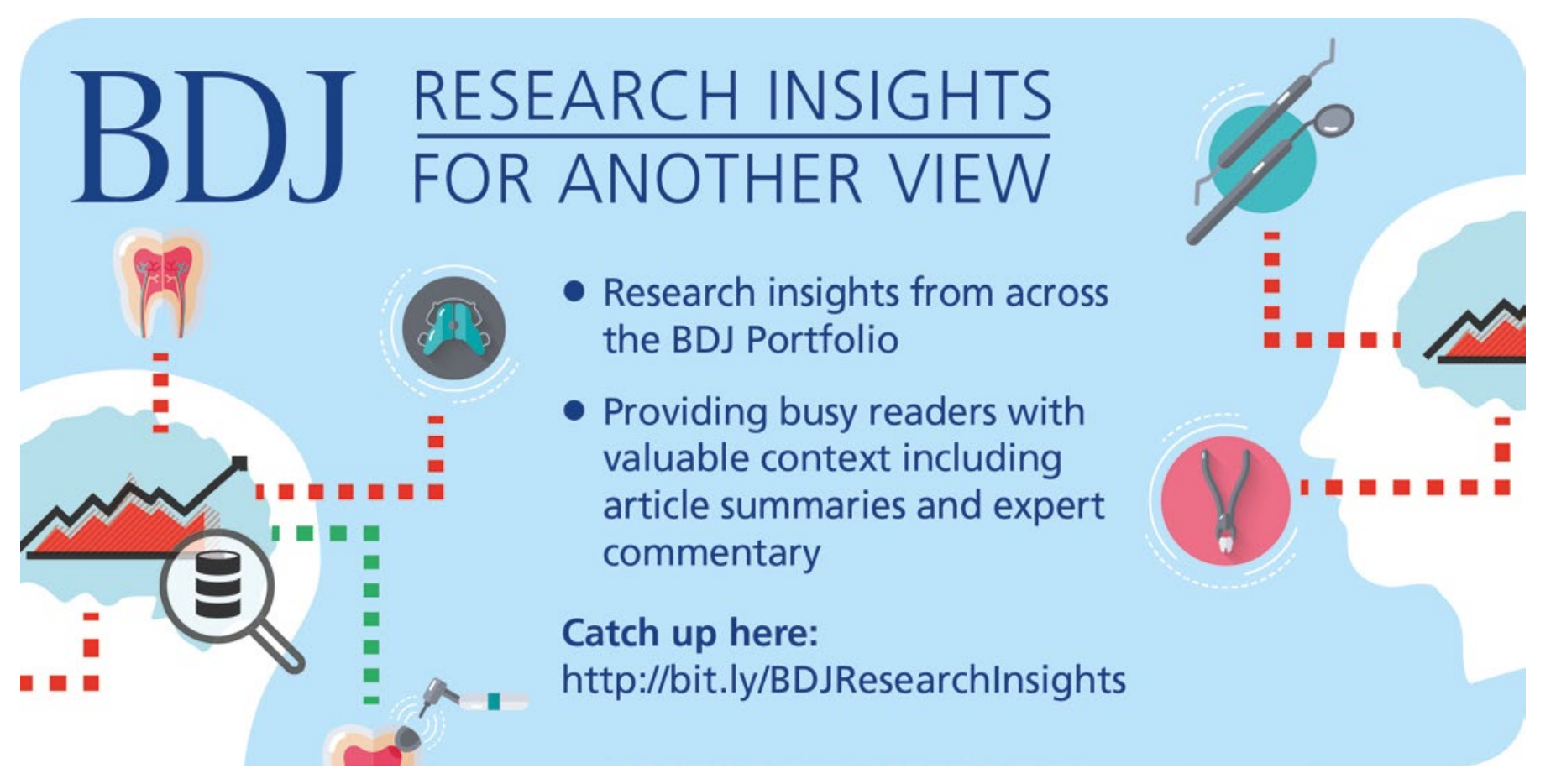

